\title{
Photodegradation of Methylene Blue Mediated by Rice Husk Ash (RHA)-TiO Composite
}

\author{
S. Ahmed*, Shirin A. Jahan, M. Zaman, Z. Yeasmin and M. Ahsan \\ Institute of Glass and Ceramic Research \& Testing (IGCRT), Bangladesh Council of Scientific and Industrial \\ Research (BCSIR), Dhanmondi, Dhaka - 1205, Bangladesh
}

\begin{abstract}
A photo-catalytic composite material incorporating rice husk ash (RHA) and $\mathrm{TiO}_{2}\left(\mathrm{RHA}: \mathrm{TiO}_{2}=75: 25\right.$ and 50:50) has been developed and used to investigate the photodegradation of the well-known dye pollutant, methylene blue (MB). Photodegradation was monitored in the dark and under illumination using a halogen lamp as well as sun light to facilitate photodegradation. Both the dark reaction and photo- mineralization processes were evaluated in terms of kinetic study which revealed the validation of first-order kinetics. A parallel measurement of chemical oxygen demand (COD) was also performed for a better understanding of the degradation process. The higher degradation rate in the sun light offers an easy-to-use and environment friendly approach for the treatment of dye stuffs. However, the overall phototdegradation mechanism involved the participation of both the anodic $\left(h^{+}\right.$consumption) and cathodic $\left(e^{-}\right.$consumption) processes which were responsible for the degradation of $\mathrm{MB}$ and consumption of dissolved oxygen respectively.
\end{abstract}

Key words: Photo-degradation, Composite plate, Rice husk ash, Methylene blue, Adsorption.

\section{Introduction}

Serious water pollution caused due to direct discharge of various industrial wastes, particularly dye pollutants, has been recognized as a threat to the environment. This has prompted researchers throughout the world to develop new, efficient and cost-effective cleaning technologies for the treatment of waste water containing dye stuffs. Dyes are extensively used in textile, leather, newsprint recycling and the dye-house wastewater usually comprises various dyes, which are toxic and harmful for both human and aquatic lives. Hence, before discharging into the environment, treatment of dye waste water is an important issue (Malik, 2003, Suteu and Biba, 2005, Zheng et. al., 2007, Mahmoodi and Arami, 2009, Mahmoodi and Arami, 2008, Arami et. al. 2008). Due to its stable nature and presence of large degree of organics in the dye stuffs, conventional physico-chemical and biological treatment procedures often become less effective to remove them from water (Malik, 2003). Although simple adsorption process and membrane separation technology are still preferred by the researchers for the treatment of dye waste water, the technological improvement of such processes will no doubt be highly beneficial.
Application of photo-catalytic method has become the stateof-the-art in treating a variety of environmental problems (Gaya and Abdullah, 2008, Rajeshwar et. al. 2001, Fujishima et. al. 2000, Fujishima and Zhang, 2006). This method has already been recognized as an alternative but attractive and efficient pathway for water purification because of its simple and easy-to-use facility. In this process the non hazardous semiconductor photo- catalyst is sensitized by the natural UV component of the sunlight or a UV source to initiate the degradation process. The photo-catalyst is usually applied in suspended (Rashed, and El-Amin, 2007, Sauer et. al. 2002) or in immobilized form (Mahmoodi and Arami, 2009, Ahmed, 2003, Bhattacharyya et. al., 2004, Kuo and Ho, 2006). Although the suspended system provides large surface area of the catalyst to precede the reaction with high efficiency, the separation and recycling of the catalyst after the treatment becomes difficult. This problem has been minimized by using the photo-catalyst in the immobilized form. However, to diversify the range of photo-sensitized degradation process, a number of products (tiles, glass, ceramic balls etc.) with photo-catalytic property have been developed for

\footnotetext{
* Corresponding author: E-mail: bcsir@yahoo.com
} 
environmental applications (Fujishima et. al. 2000, Fujishima and Zhang, 2006).

Bangladesh is a developing country where discharge of industrial waste is a major problem and most of the industries are directly releasing the unwanted toxic, hazardous wastes into the rivers and or in nearby ponds. The increasing urbanization and industrialization in Bangladesh have negative impact for water quality and at present it has reached to an alarming proportion (Chowdhury, and Clemett, 2006, Sultana et. al. 2009). In this research work an attempt has been made to develop a simple but highly active and environment friendly process for the treatment of industrial waste water which is expected to have a greater impact in the economic development of the country. Primarily, photo-catalyst incorporating low cost composite material has been developed which can be used to treat industrial waste water before flushing to the environment. Since rice husk ash (RHA) is a waste material and acts as an adsorbent (Malik,2003, Mahvi et. al. 2004), the approach was to use
RHA with $\mathrm{TiO}_{2}$ (Degussa P25, one of the most active photocatalyst) to develop such composite material to follow the degradation and adsorption of the pollutants. To examine the efficacy of this newly developed composite material methylene blue (MB) [Alzaydein, 2009, Mills and Wang, 1999] was treated using halogen lamp and sun light. Since no high temperature is required to produce the photo-catalytic composite material and the sun light initiates the photo-sensitized reaction, this method is expected to be beneficial in two ways: (i) easy-to-use procedure for dye waste water treatment, and (ii) utilization of RHA is a promising material recycling technology for future waste management.

\section{Materials and Methods}

\section{Chemicals}

$\mathrm{MB}$ and $\mathrm{TiO}_{2}$ were obtained from Aldrich and Degussa respectively; RHA was collected from local rice mill which was a waste product obtained through uncontrolled burning in the mill. All the solutions of desired concentrations were prepared using double distilled water.

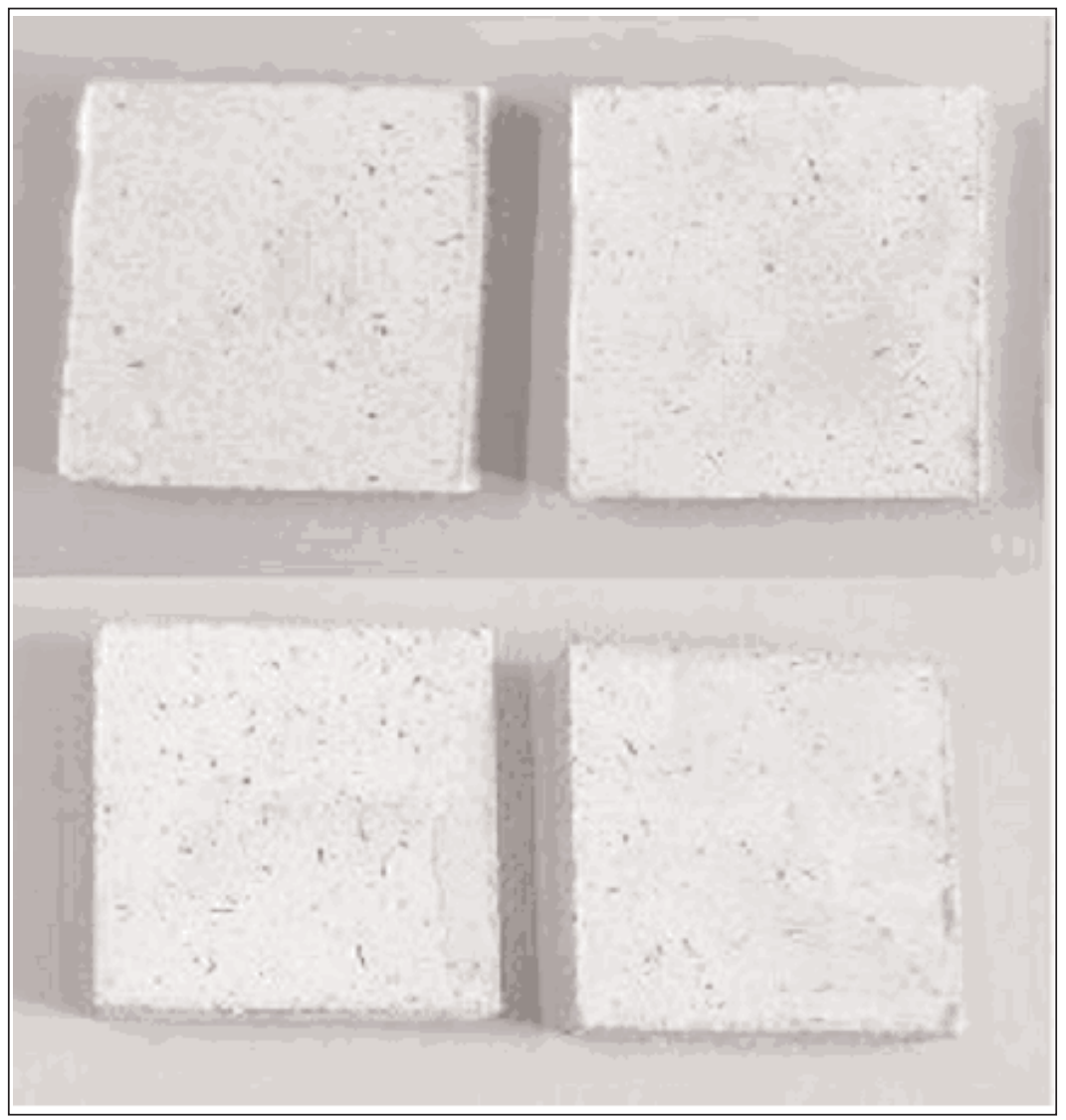

Fig. 1: Photograph of $\mathrm{RHA}^{-\mathrm{TiO}_{2}}$ (top - 25\% $\mathrm{TiO}_{2}$, bottom - 50\% $\mathrm{TiO}_{2}$ ) composite 
Preparation of $\mathrm{RHA}-\mathrm{TiO}_{2}$ composite photo-catalytic material

RHA- $\mathrm{TiO}_{2}$ photo-catalytic composite materials were prepared by a simple method. A requisite amount of RHA was mixed with $\mathrm{TiO}_{2}$ maintaining the photo-catalyst ratio at $0 \%$, $25 \%$ and $50 \%$. It was then mixed thoroughly in a ball mill under aqueous suspended condition. After completing the ball mill operation the mixture was heated at $10^{\circ} \mathrm{C}$ just to evaporate the excess water and $\sim 5.0 \mathrm{~mL}$ of sodium silicate solution was added to it as the binder. The mixture was then shaped into $5.0 \mathrm{~cm} \times 5.0 \mathrm{~cm} \times 0.625 \mathrm{~cm}$ rectangular size using mold and dried at ambient temperature. A pressure of 3 ton was applied to make it in compact form and final product was obtained by further heating at $10^{\circ} \mathrm{C}$ for an hour. Figure 1 shows the photograph of these finished composites.

\section{Adsorption of MB (dark reaction)}

Since adsorption phenomenon is an important parameter in the photo-catalytic process, prior to the photo-degradation study, the dark reaction of MB in the presence of $\mathrm{RHA}^{-\mathrm{TiO}_{2}}$ composite was carried out at an initial dye concentration of $1.0 \times 10^{-5} \mathrm{~mol} \mathrm{dm}^{-3}$ in monomer form (Mills and Wang,

1999). This monomeric form of MB exhibits the absorption maximum at $\sim 660 \mathrm{~nm}$. The composite was placed vertically into the pyrex reactor $(10 \mathrm{~cm} \times 10 \mathrm{~cm} \times 10 \mathrm{~cm})$ containing 100 $\mathrm{mL}$ MB solution and was kept in the dark for $2 \frac{1}{2} \mathrm{hrs}$ followed by measuring the residual dye concentration at a regular time interval of 30 mins.

Treatment of model dye pollutant using $\mathrm{RHA}^{-\mathrm{TiO}_{2}}$ composite

The photodegradation of MB was investigated using the same pyrex reactor and the composite was placed vertically into the reactor as described in the previous section. 1.0 $\times 10^{-5} \mathrm{~mol} \mathrm{dm}^{-3}$ aqueous solution of MB was chosen for the treatment providing indoor illumination through a halogen lamp while the sun light facilitated the out door irradiation. An infrared filter filled with ultra-pure water was used to avoid heating of the reactor during irradiation and this also defined the wavelength of the illumination source as between $200-800 \mathrm{~nm}$. Maximum illumination was achieved by using a focusing lense. A magnetic stirrer was used to facilitate continuous stirring of the substrate solution during reaction. For both cases the fate of the photodegradation reactions were monitored as a function of time using the RHA composite

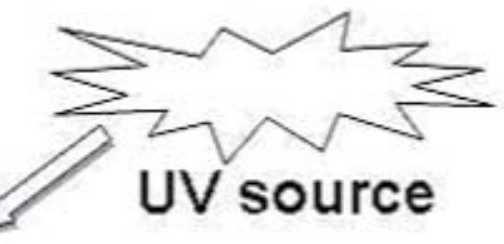

\section{Mirror}

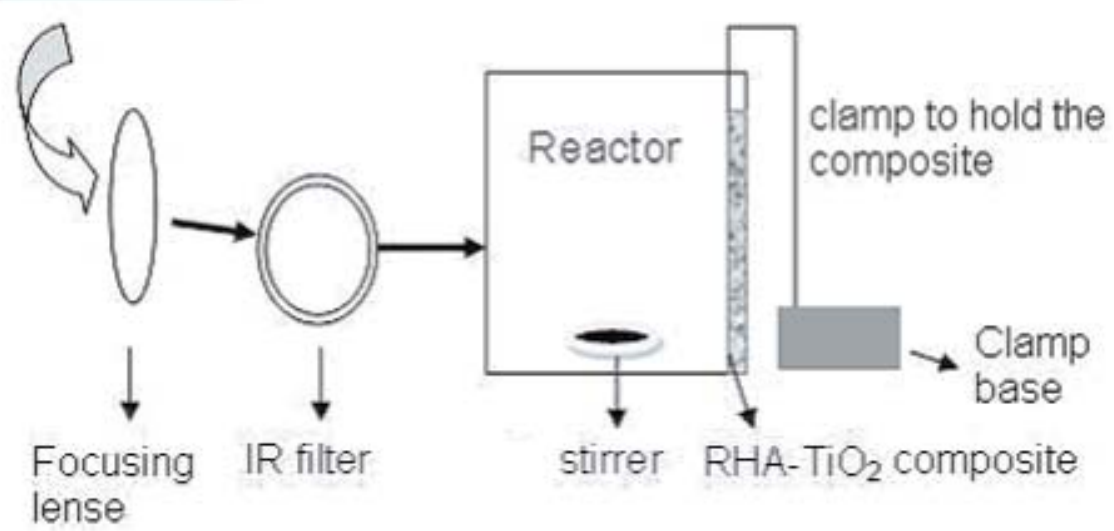

Fig. 2: Schematic of the photo-catalytic experimental set up 
plate containing $0 \% \mathrm{TiO}_{2}, 25 \% \mathrm{TiO}_{2}$ and $50 \% \mathrm{TiO}_{2}$ as photo-catalyst. Chemical oxygen demand (COD) of the on going photo-process was measured by using the potassium dichromate method (Taicheng et. al. 2001). Figure 2 shows the schematic diagram of the experimental set up. The intensity of the halogen lamp and sun light was determined by potassium ferrioxalate actinometry method (Hatchard and Parker, 1956).

\section{Method of analyses}

The molar extinction co-efficient of $\mathrm{MB}$ at $660 \mathrm{~nm}$ is $10^{5}$ $\mathrm{dm}^{3} \mathrm{~mol}^{-1} \mathrm{~cm}^{-1}$ (Mills and Wang, 1999). The concentration of the residual dye at the time interval $(\mathrm{t})$ was obtained by measuring the absorbance at $\lambda_{\max }=660 \mathrm{~nm}$ using the UV/visible spectrophotometer. The performance of the composite material toward the dark and illumination reactions was monitored in terms of percent of degradation according to the following equation:

$\%$ of adsorptial or degradtion $=\frac{C_{0}-C_{1}}{C_{0}} \times 100$

where $C_{\mathrm{o}}=$ initial concentration and $C_{\mathrm{t}}=$ concentration at time $\mathrm{t}$

However, in case of the dark reaction the amount of $\mathrm{MB}$ adsorbed per unit mass $\left(\mathrm{q}_{\mathrm{t}}, \mathrm{mg} \mathrm{g}^{-1}\right)$ was calculated as,

$$
q_{\mathrm{t}}=\frac{C_{0}-C_{1}}{m} V
$$

where, $m=$ mass of the composite $(25 \mathrm{~g})$ and $V=$ volume of MB solution $(100 \mathrm{~mL})$.

The kinetics of the adsorption was investigated due to its importance in waste water treatment process. Hence the adsorption kinetics was interpreted in terms of both firstorder rate equation based on the solution concentration (Equation 3) and pseudo-second-order kinetic model based on the sorption equilibrium capacity (Equation 4) (Bhakat et. al. 2006).

$$
\begin{gathered}
\text { In }=\frac{C_{0}}{C_{t}}=k_{l} t \\
\frac{t}{q_{t}}=\frac{1}{q_{e}} t+\frac{1}{k_{2} q_{e}^{2}}
\end{gathered}
$$

where, $k_{1}\left(\min ^{-1}\right)$ and $\mathrm{k}_{2}\left(\mathrm{~g} \mu \mathrm{g}^{-1} \mathrm{~min}^{-1}\right)$ are the first-order and pseudo-second-order rate constants respectively, $q_{\mathrm{e}}=$ amount of $\mathrm{MB}$ adsorbed after reaching the equilibrium $\left(\mu \mathrm{g} \mathrm{g}^{-1}\right)$.

However, on the other hand it is well known that $\mathrm{TiO}_{2}$ sensitized complete photo-degradation process occurs via the simultaneous oxidation $\left(h^{+}\right.$consumption) and reduction $\left(e^{-}\right.$ consumption) reactions at the excited catalyst surface. The photogenerated $\mathrm{h}^{+}$reacts with $\mathrm{H}_{2} \mathrm{O}$ resulting the strong oxidizing agent $\mathrm{OH}^{\bullet}$ radical (standard redox potential $+2.8 \mathrm{~V}$ ) which actively decomposes MB to the mineral end products. While the photogenerated $e^{-}$reacts with the dissolved oxygen producing super oxide anions which also participates in the degradation process as shown in equation (7).

The overall degradation of MB proceeds through the following reaction,

$$
\begin{gathered}
\mathrm{C}_{16} \mathrm{H}_{18} \mathrm{~N}_{3} \mathrm{SCl}+25.5 \mathrm{O}_{2} \stackrel{h v+T_{i} \mathrm{O}_{2}}{\longrightarrow} \mathrm{HCl}+ \\
\mathrm{H}_{2} \mathrm{SO}_{4}+3 \mathrm{HNO}_{3}+16 \mathrm{CO}_{2}+6 \mathrm{H}_{2} \mathrm{O}
\end{gathered}
$$

where, anodic and cathodic reactions can be expressed as follows:

Anodic (oxidation) reaction: $h^{+}+\mathrm{H}_{2} \mathrm{O} \rightarrow \mathrm{H}^{+}+\mathrm{OH}^{\bullet} \rightarrow$

$$
\text { Degradation of } \mathrm{MB}
$$

Cathodic (reduction) reaction:

$$
e^{-}+\mathrm{O}_{2} \rightarrow \mathrm{O}_{2}^{-\bullet} \rightarrow \mathrm{H}_{2} \mathrm{O}_{2} \rightarrow \mathrm{H}_{2} \mathrm{O}
$$

It is clear from the above degradation stoichiometry that to complete the reaction, 25.5 molecule of $\mathrm{O}_{2}$ reacts with per MB molecule, which also ensures the simultaneous consumption of dissolved oxygen throughout the degradation process. Previous investigation (Mills and Wang, 1999) also discussed that for complete mineralization of $1.0 \times 10^{-5}$ mol dm$~^{-3}$ aerated $\mathrm{MB}$ solution, all the dissolved oxygen $\left(2.5 \times 10^{-4} \mathrm{~mol} \mathrm{dm}^{-3}\right)$ present in the solution was required. Simultaneous consumption of oxygen during the photodegradation of 4-chlorophenol has also been reported by others (Ahmed, 2003, Fonseca et. al. 2004, Fonseca et. al. 2003). However, the possible reaction mechanisms which contribute the degradation of MB is a combination of oxidation and reduction processes involving (i) direct oxidation of MB by hydroxyl radical ( $h^{+}$consumption), and (ii) reduction of oxygen by the superoxide anion ( $e^{-}$consumption). Hence, 
the overall degradation process will be a combination of anodic and cathodic (oxidation and reduction) reactions. Considering this critical point, MB degradation and oxygen consumption were monitored with time and the data were analyzed through the apparent first-order rate equation (equation 8) which is the simplified form of LangmuirHinshelwood kinetic model (Rashed et. al.,2007).

$$
\ln \frac{C_{0}}{C_{t}}=k_{a p p} t
$$

Where $k_{\text {app }}$ is the apparent first-order rate constant $\left(\mathrm{min}^{-1}\right)$

\section{Results and Discussion}

\section{Analysis of RHA}

The major elemental composition of RHA was determined by conventional methods which revealed the presence of $\mathrm{SiO}_{2}(91.3 \%), \mathrm{Al}_{2} \mathrm{O}_{3}(0.15 \%), \mathrm{Fe}_{2} \mathrm{O}_{3}(0.12 \%), \mathrm{CaO}(0.21 \%)$, $\mathrm{MgO}(0.31 \%), \mathrm{Na}_{2} \mathrm{O}(1.52 \%), \mathrm{K}_{2} \mathrm{O}(2.65 \%), \mathrm{TiO}_{2}(0.15 \%)$, $\mathrm{SO}_{3}(0.24 \%)$ and loss on ignition (2.7\%) (Farooque, 2006). This RHA is porous in nature which is responsible for its high specific surface (Farooque, 2006). For this reason RHA was chosen with $\mathrm{TiO}_{2}$ to develop the highly efficient photocatalytic composite material to treat the dye pollutants.

\section{Adsorption of MB}

The adsorption efficiency of the composite is shown in Fig. 3. It is clearly evident from Fig. 3 that the adsorption process increased linearly up to $1 \frac{1}{2} \mathrm{hrs}$ then reached the equilibrium by $2 \frac{1}{2} \mathrm{hrs}$ time.

The kinetics of adsorption process was analyzed through the first- and second-order adsorption kinetic models (Equations 3 and 4). The experimental data plotted in the graphs as shown in Figs. $4 \mathrm{a}$ and $4 \mathrm{~b}$ respectively. For both models the corresponding adsorption parameters were derived from the respective slopes and intercepts which are summarized in Table I. The calculated regression values $\left(\mathrm{R}^{2}\right)$ in Table I shows that the first-order kinetics describe the adsorption phenomenon better than that of the pseudo second-order kinetic model.

\section{Photodegradation of $\mathrm{MB}$ without $\mathrm{TiO}_{2}$}

The observed percent of photodegradation of $\mathrm{MB}$ in the presence of only RHA (i.e. $0 \% \mathrm{TiO}_{2}$ ) was very close to that

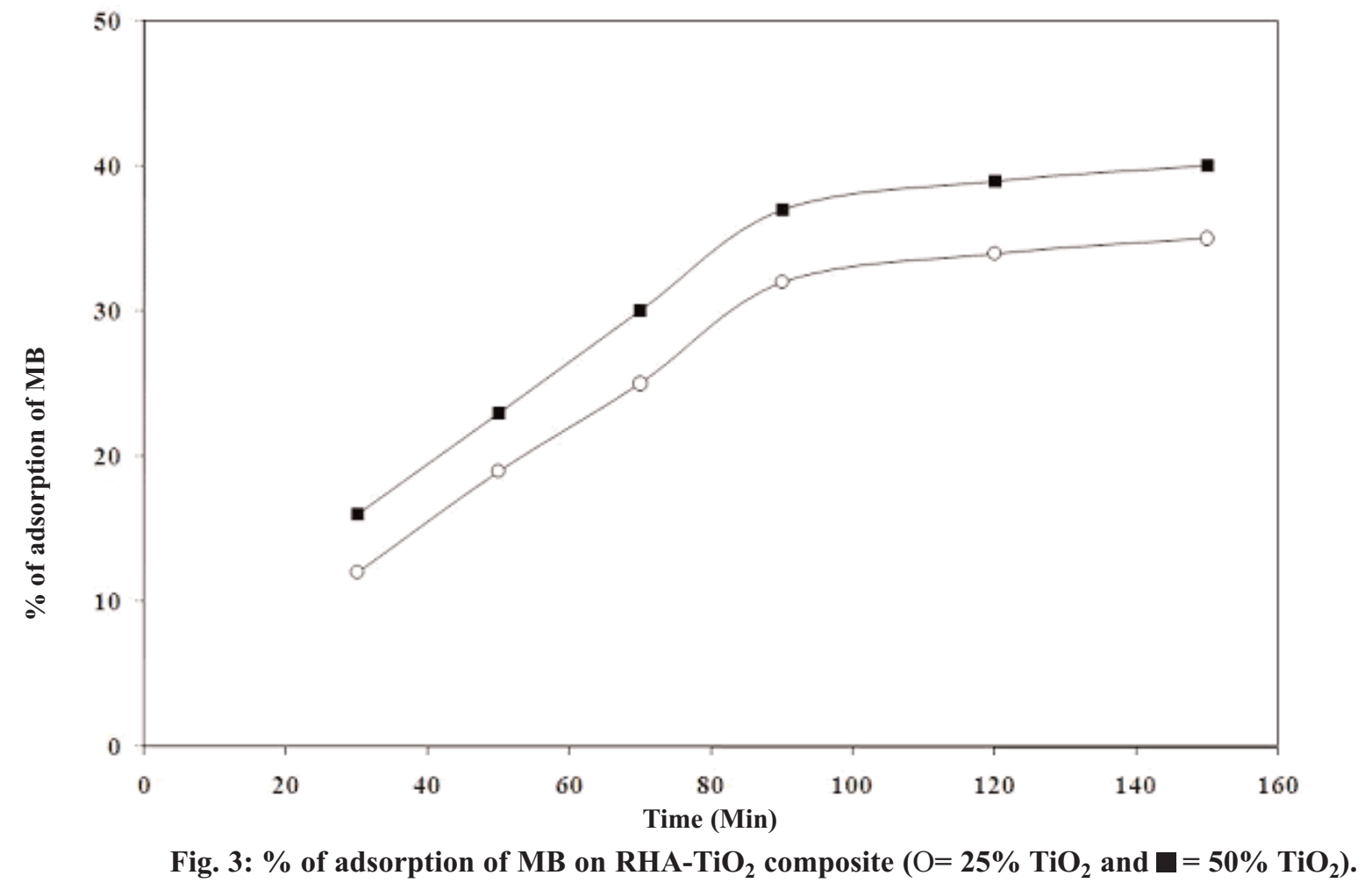




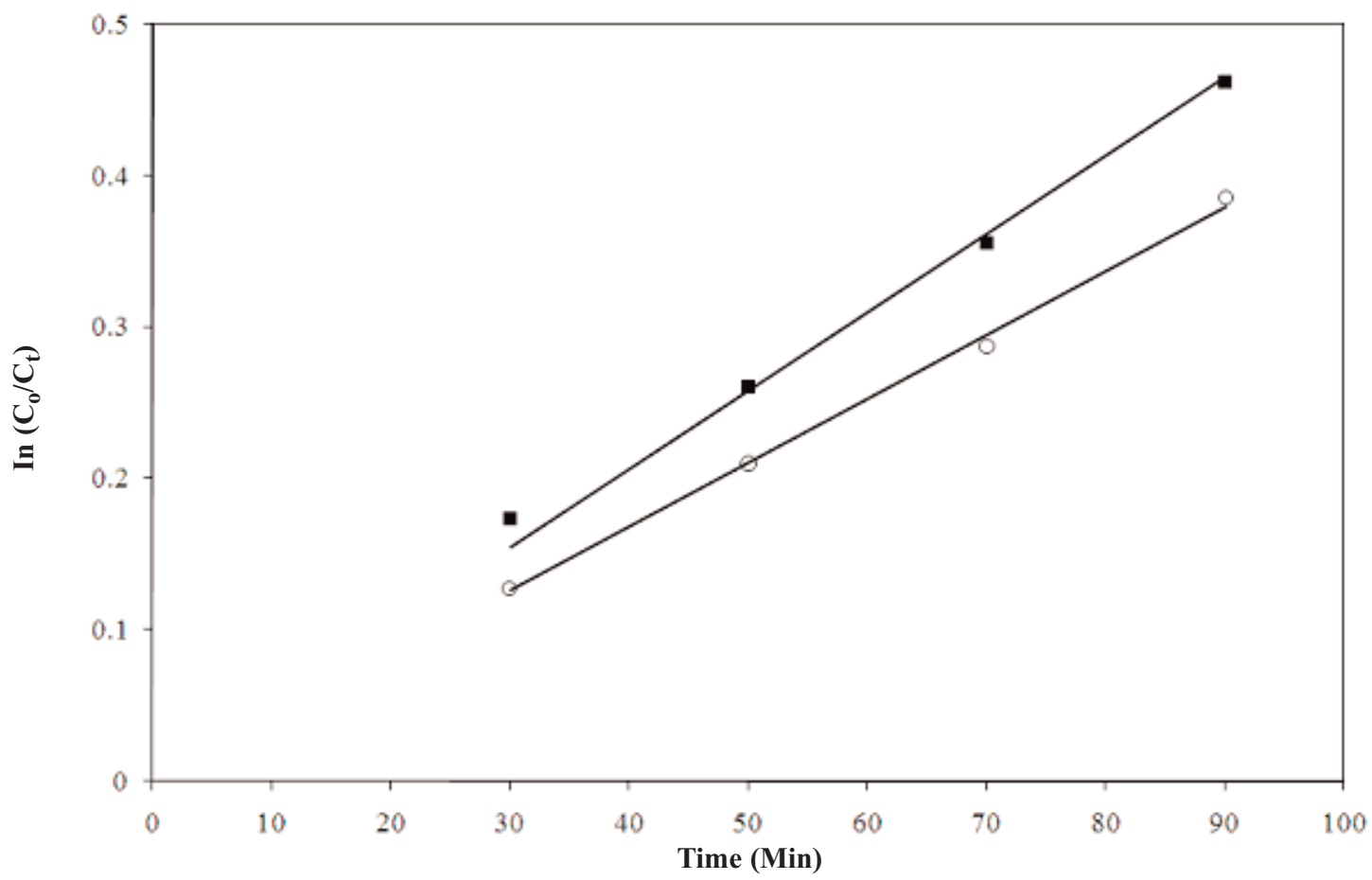

Fig. 4a: First-order adsorption kinetics of $\mathrm{MB}$ on $\mathrm{RHA}-\mathrm{TiO}_{2}$ composite $\left(\mathrm{O}=\mathbf{2 5 \%} \mathrm{TiO}_{2}\right.$ and $\left.\square=50 \% \mathrm{TiO}\right)$.

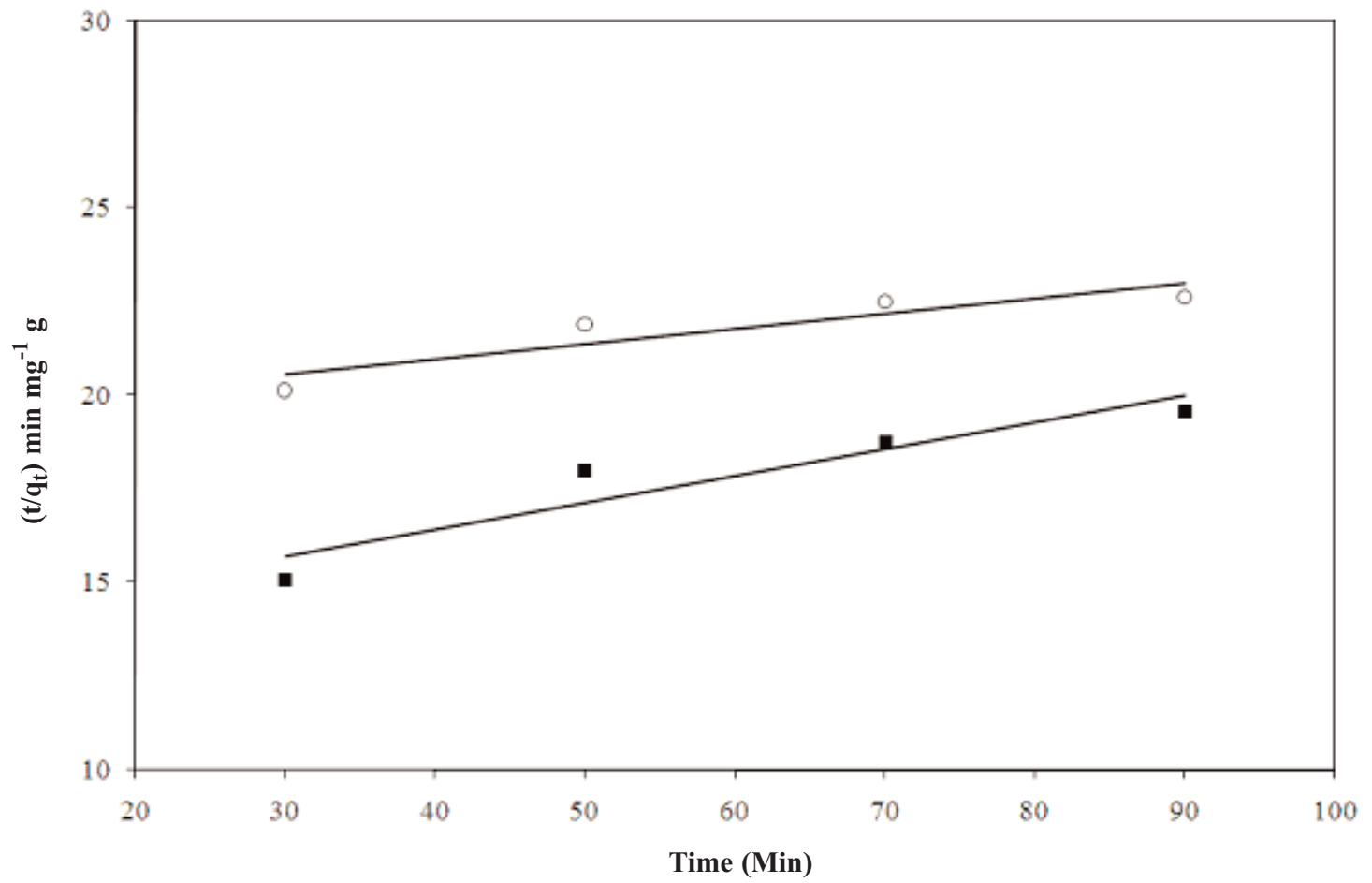

Fig. 4b: Pseudo-second-order adsorption kinetics of $\mathrm{MB}$ on $\mathrm{RHA}-\mathrm{TiO}_{2}$ composite $\left(\mathrm{O}=\mathbf{2 5} \% \mathrm{TiO}_{2}\right.$ and $\left.\square=50 \% \mathrm{TiO}_{2}\right)$. 
Table I: Adsorption kinetic parameters.

\begin{tabular}{|c|c|c|c|c|c|}
\hline \multirow{2}{*}{$\begin{array}{c}\% \text { of } \mathrm{TiO}_{2} \text { in } \\
\text { composite plate }\end{array}$} & \multicolumn{2}{|c|}{ First-order kinetics } & \multicolumn{3}{|c|}{ Pseudo-second-order kinetics } \\
\hline & $\begin{array}{l}\text { Rate constant } k_{1} \\
\qquad\left(\mathrm{~min}^{-1}\right)\end{array}$ & $\mathrm{R}^{2}$ & $\begin{array}{c}\mathrm{qe}_{\mathrm{e}} \\
\mathrm{g} \mathrm{g} \mathrm{g}^{-1}\end{array}$ & $\begin{array}{l}\text { Rate constant } k_{2} \\
\left(\mathrm{~g} \mu \mathrm{g}^{-1} \mathrm{~min}^{-1}\right)\end{array}$ & $\mathrm{R}^{2}$ \\
\hline $\begin{array}{l}25 \\
50\end{array}$ & $\begin{array}{l}0.004 \\
0.005\end{array}$ & $\begin{array}{l}0.997 \\
0.991\end{array}$ & $\begin{array}{c}25.0 \\
14.08\end{array}$ & $\begin{array}{l}8.26 \times 10^{-5} \\
3.71 \times 10^{-4}\end{array}$ & $\begin{array}{l}0.821 \\
0.878\end{array}$ \\
\hline
\end{tabular}

value as observed in case of the adsorption or dark reaction. This indicated that even though illumination was facilitated, the percent of degradation of MB did not increase from that adsorption value due to the absence of $\mathrm{TiO}_{2}$.

\section{Photodegradation of $\mathrm{MB}$ in the presence of $\mathrm{TiO}_{2}$}

Upon illumination the photogenerated $h^{+}$being a very strong oxidizing agent started decomposing MB promptly. The percent of photodegradation of $\mathrm{MB}$ at the RHA-TiO composite $_{2}$ (containing $25 \%$ and $50 \% \mathrm{TiO}_{2}$ ) was recorded as a function of time and the resulting graphs are shown in Fig. 5. In case of both the illumination sources (halogen lamp, intensity $1.68 \times 10^{16} \mathrm{q} \mathrm{cm}^{-3} \mathrm{~s}^{-1}$ and sun light, intensity $4.94 \times 10^{16} \mathrm{q}$ $\mathrm{cm}^{-3} \mathrm{~s}^{-1}$ ) the observed photodegradation increased with reaction time and the corresponding plots showed a rapid increase in degradation up to $1 \frac{1}{2} \mathrm{hrs}$, then the rate of the reaction became slow. It is evident from the Fig. 5 that although both indoor and out door illumination favoured the photo-degradation process, yet the effect of different irradiation sources is a major factor, since the photo-generation of $e^{-} / h^{+}$pair depends on the energy of the source light. Hence, the treatment procedure using the sun light having an effective intensity of $4.94 \times 10^{16} \mathrm{q} \mathrm{cm}^{-3} \mathrm{~s}^{-1}$ resulted a high degradation as observed in previous study performed by Rashed et. al., 2007. In-order to further examine the activity of the developed composite, percent of COD consumption was measured only for the case of $\mathrm{MB}$ degradation under sun light using $\mathrm{RHA}^{-\mathrm{TiO}_{2}}(50 \%)$ composite and based on Equation (1) and the corresponding graph (Figure 5) showed that the percent of COD consumption followed similar trend to that of the MB degradation percent. However, it is evident

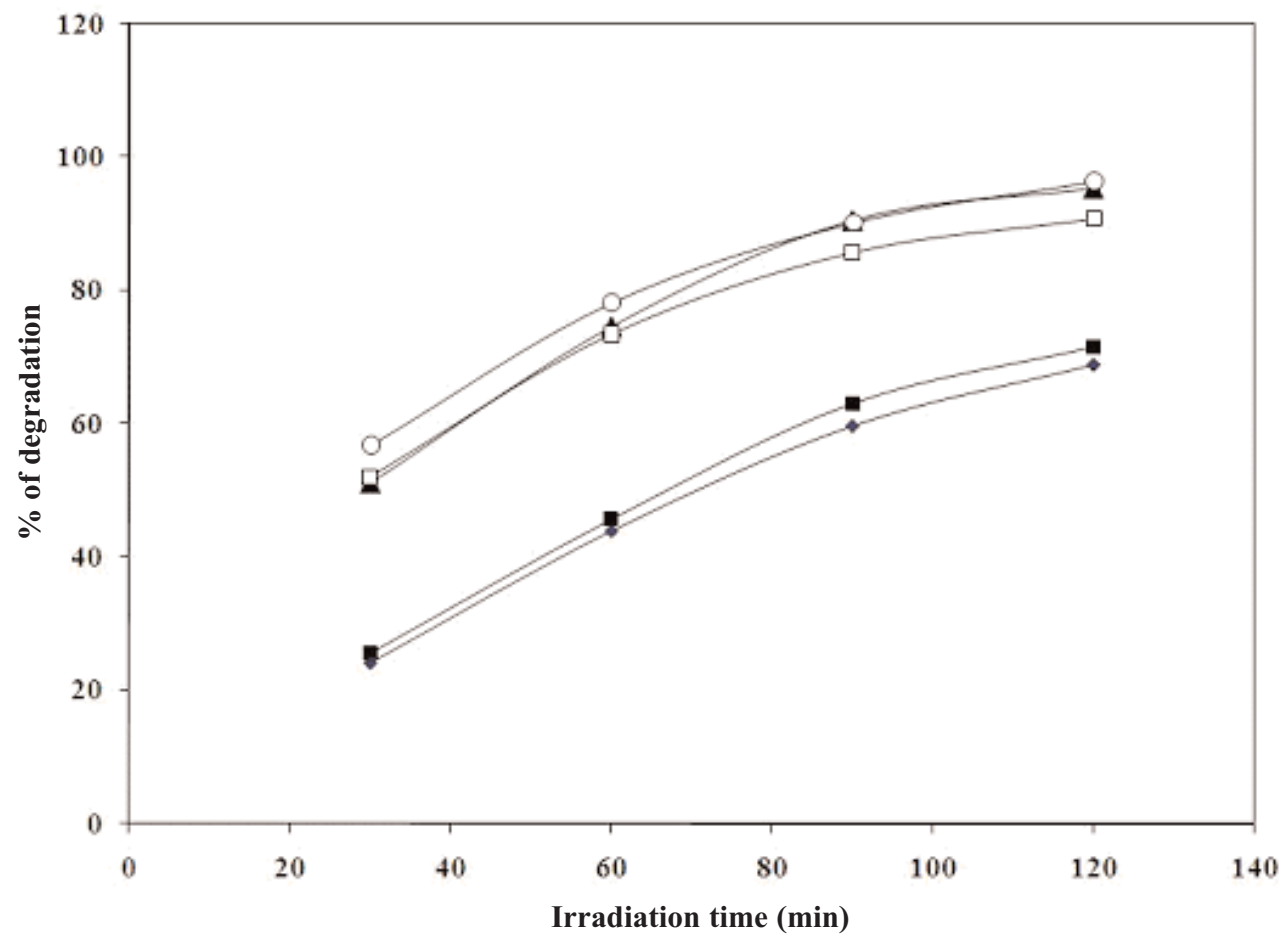

Fig. 5: \% of degradation of $\mathrm{MB}$ and $\mathrm{O}_{2}$ on $\mathrm{RHA}-\mathrm{TiO}_{2}$ composite (MB degradation under halogen lamp using 25\% $\mathrm{TiO}_{2}=\mathrm{u}$, and $50 \% \mathrm{TiO}_{2}=\mathrm{n} \mathrm{MB}$ degradation under sun light using $25 \% \mathrm{TiO}_{2}=\mathrm{s}$, and $\mathbf{5 0} \% \mathrm{TiO}_{2}=\mathrm{O}=\mathrm{O}_{2}$ consumption under sun light using $50 \% \mathrm{TiO}_{2}$ ). 
from Fig. 5 that the degradation percentage of $\mathrm{MB}$ is slightly higher than that of COD removal percentage. The experimental data for MB degradation $\left(h^{+}\right.$consumption by anodic reaction) and oxygen depletion ( $e^{-}$consumption by cathodic reaction) were interpreted in terms of first-order kinetic model as discussed in the previous section. For both cases, the plots of $\ln \left(\mathrm{C}_{0} / \mathrm{C}_{\mathrm{t}}\right)$ vs time (Fig. 6) resulted in straight lines as expected and the gradients of these plots upon linear regression equals the apparent first-order rate constants which are summarized in Table II. The rates of the photoprocesses were obtained using the following equation:

$$
\text { rate }=\text { gradient }\left[C_{0}\right]
$$

It is clear from the data of Table II that in case of MB degradation (using 50\% $\mathrm{RHA}^{-\mathrm{TiO}_{2}}$ composite and sun light), the observed degradation rate is $2.6 \times 10^{-7} \mathrm{~mol} \mathrm{dm}^{-3} \mathrm{~min}^{-1}$ while the corresponding oxygen consumption rate is $5.6 \times 10^{-6} \mathrm{~mol}$ $\mathrm{dm}^{-3} \mathrm{~min}^{-1}$ which is almost 22 fold higher. This indicates that to decompose one MB molecule 22 molecule of oxygen was required. This value is very close to the theoretical value (Equation 5) which showed that 25.5 molecule of oxygen is consumed per MB molecule decomposition. The discrepancy between the theoretical and observed value could be due to the involvement of various unknown intermediates in the oxidative photo-destruction of $\mathrm{MB}$, since it adsorbs on the surface of the adsorbent (Rashed et. al.,2007). The observed depletion in dissolved oxygen concentration indicated that the presence of oxygen is necessary for a photodegradation reaction. Thus the photodegradation reaction must proceed towards the mineral end products through the participation of both anodic and cathodic reactions.

It is obvious from the present results that the efficiency of the composite material toward adsorption and photo-mineralisation of $\mathrm{MB}$, achieved by using $\mathrm{RHA}-\mathrm{TiO}_{2}$ (either $50 \%$ or $25 \% \mathrm{TiO}_{2}$ ) were almost same under the present experimental condition. However, further work is needed to optimize the photodegradation experimental protocol with regard to catalyst dose, initial concentration, $\mathrm{pH}$ of the solution etc. and works in this direction are in progress.

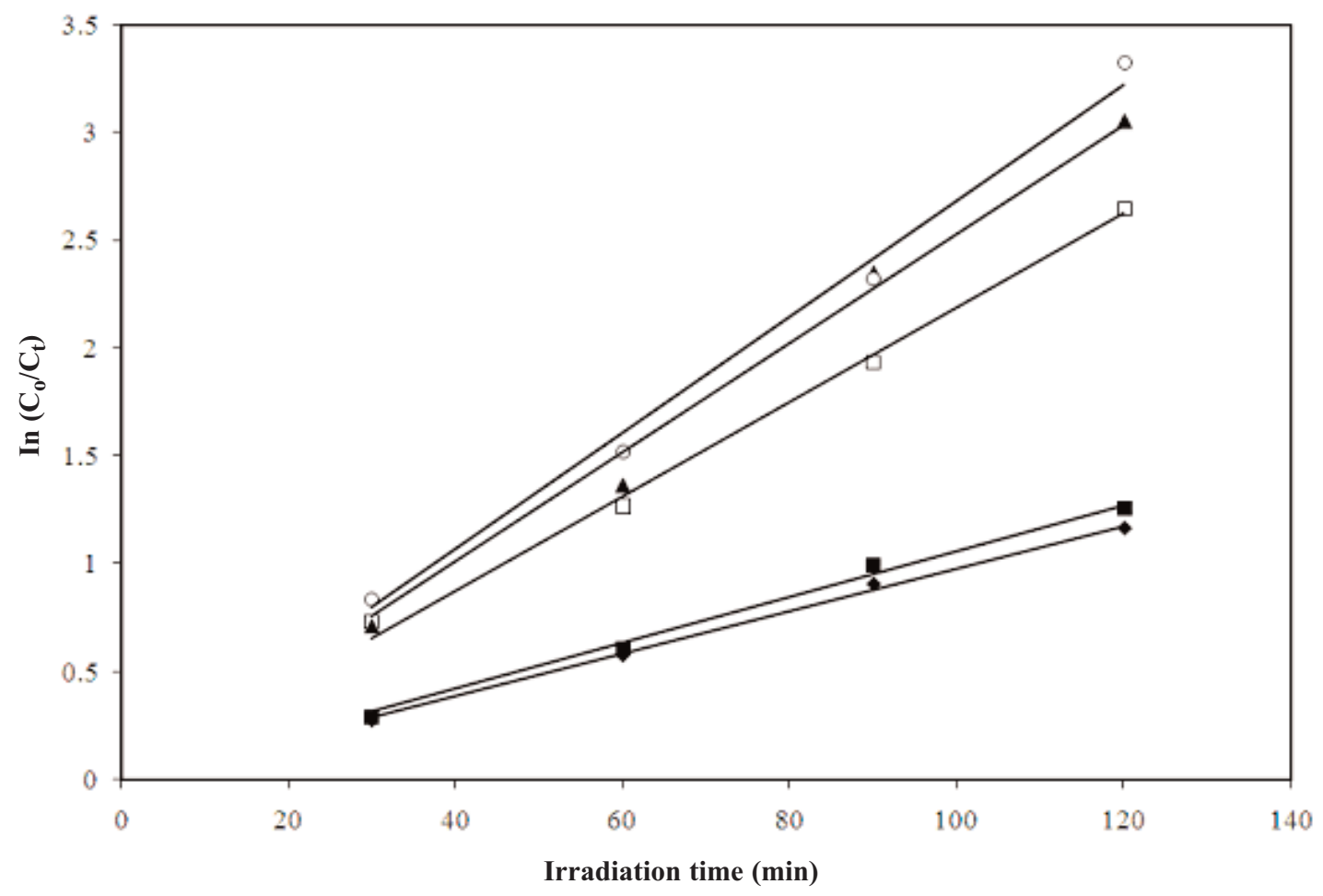

Fig. 6: First-order photo-degradation kinetics of $\mathrm{MB}$ degradation and $\mathrm{O}_{2}$ consumption on $\mathrm{RHA}-\mathrm{TiO}_{2}$ composite (MB degradation under halogen lamp using 25\% $\mathrm{TiO}_{2}=\mathrm{u}$, and $50 \% \mathrm{TiO}_{2}=\mathrm{n}$. MB degradation under sun light using $25 \% \mathrm{TiO}_{2}=\mathrm{s}$, and $50 \% \mathrm{TiO}_{2}=\mathrm{O} . \quad=\mathrm{O}_{2}$ consumption under sun light using $\mathbf{5 0 \%} \mathrm{TiO}_{2}$ ) 
Table II: First-order kinetic parameters for $\mathrm{MB}$ degradation and $\mathrm{O}_{2}$ consumption.

\begin{tabular}{|c|c|c|c|c|c|c|}
\hline \multirow{3}{*}{$\begin{array}{c}\% \text { of } \mathrm{TiO}_{2} \text { in } \\
\text { composite } \\
\text { material }\end{array}$} & \multicolumn{3}{|c|}{ Halogen lamp } & \multicolumn{3}{|c|}{ Sun light } \\
\hline & $\begin{array}{l}\text { Rate constant } k_{\text {app }} \\
\qquad\left(\mathrm{min}^{-1}\right)\end{array}$ & $\begin{array}{l}\text { Degradation rate } \\
\left(\mathrm{mol} \mathrm{dm}^{-3} \mathrm{~min}^{-1}\right)\end{array}$ & $\mathrm{R}^{2}$ & $\begin{array}{c}\text { Rate constant } \\
k_{\text {app }}\left(\min ^{-1}\right)\end{array}$ & $\begin{array}{c}\text { Degradation / con- } \\
\text { sumption rate } \\
\left(\mathrm{mol} \mathrm{dm} \mathrm{dm}^{-3} \mathrm{~min}^{-1}\right)\end{array}$ & $\mathrm{R}^{2}$ \\
\hline & \multicolumn{6}{|c|}{ Degradation of MB $\left(\mathrm{C}_{0}=1.0 \times 10^{-5} \mathrm{~mol} \mathrm{dm}^{-3}\right)$} \\
\hline 25 & 0.009 & $9.0 \times 10^{-8}$ & 0.997 & 0.025 & $2.5 \times 10^{-7}$ & $0 . .990$ \\
\hline \multirow[t]{3}{*}{50} & \multirow[t]{3}{*}{0.01} & \multirow[t]{3}{*}{$10.0 \times 10^{-8}$} & \multirow[t]{3}{*}{0.993} & 0.026 & $2.5 \times 10^{-7}$ & $0 . .991$ \\
\hline & & & & \multicolumn{3}{|c|}{$\begin{array}{c}\text { Consumption of } \mathrm{O}_{2} \\
\left(\mathrm{C}_{0}=2.5 \times 10^{-4} \mathrm{~mol} \mathrm{dm}^{-3}\right)\end{array}$} \\
\hline & & & & 0.022 & $5.6 \times 10^{-6}$ & 0.995 \\
\hline
\end{tabular}

\section{Conclusion}

The developed cost-effective $\mathrm{RHA}_{-} \mathrm{TiO}_{2}$ composite material effectively treats $\mathrm{MB}$ the well known representative of the polluting dye stuffs. Both adsorption and photo-catalytic destruction revealed that this could be a potential approach in treating the industrial waste water which will have a great impact in the economic development of the country. The experimental value of $\mathrm{MB}$ photodegradation and $\mathrm{O}_{2}$ consumption rates showed simultaneous involvement of $h^{+}$(oxidation of MB through anodic process) and $e^{-}$(reduction of $\mathrm{O}_{2}$ through cathodic process) during the photo-degradation process. However, to optimize this technology, effect of various parameters i.e. dose of the photo-catalyst, $\mathrm{pH}$ of the solution, concentration of the substrate etc. need to be considered.

\section{Acknowledgement}

The authors gratefully acknowledge the financial support from IGCRT, BCSIR.

\section{References}

Ahmed. S. (2003). Probing the extent of $\left[\mathrm{O}_{2}\right]$ depletion and $\left[\mathrm{Cl}^{-}\right]$production simultaneously at.an illuminated surface employing simple electrochemical methods. $J$. Photochem. Photobiol. A: Chem. 154: 229-134.

Alzaydein. A. S (2009). Adsorption of methylene blue from aqueous solution, Am. J. Environ. Sci. 5(3): 197-208.

Arami. M., Limaee. N. Y. and Mahmoodi. N. M. (2008). Evaluation and adsorption kinetics and equilibrium for the potential removal of acid dyes using a biosorbent, Chem. Eng. J. 139: 2-10.

Bhakat. P. B., Gupta. A. K., Ayoob. S. and Kundu. S. (2006). Investigation on arsenic (V) removal by modified calcined bauxite, Colloids and Surfaces A: Physicochem. Eng. Aspects, 281: 237-245.

Bhattacharyya. A., Kawi. S. and Ray. M. B. (2004). Photocatalytic degradation of orange II by $\mathrm{TiO}_{2}$ catalysts supported on adsorbents, Catal. Today, 98: 431439.

Chowdhury. N. S. and Clemett. A. E. V. (2006) Industrial pollution and its threat to Mokesh Beel wetland in Kaliakoir, MACH technical report, Dhaka.

Farooque. K. N. (2006). Studies on physico-chemical properties of some cement composites from rice husk ash and other materials, $\mathrm{PhD}$ Thesis, University of Dhaka.

Fonseca. S. M., Barker. A. L., Ahmed. S., Kemp. T. J. and Unwin. P. R. (2004). Scanning electrochemical microscopy investigation of the photodegradation kinetics of 4-chlorophenol sensitized by $\mathrm{TiO}_{2}$ films, Phys. Chem. Chem. Phys, 6: 5218-5224.

Fonseca. S.M., Barker. A. L., Ahmed. S., Kemp. T. J. and Unwin. P. R. (2003). Direct observation of oxygen depletion and product formation during photocatalysis of a $\mathrm{TiO}_{2}$ surface using scanning electrochemical microscopy, Chem. Commun., 1002-1003. 
Fujishima. A, Rao. T. N. and Tryk. D. A. (2000). Titanium dioxide photocatalysis, J. Photochem. Photobiol. C: Photochemistry Reviews 1: 1-21.

Fujishima. A. and Zhang. X. (2006). Titanium dioxide photocatalysis: present situation and future approaches, $C$. R. Chimie, 9: 750-760.

Gaya. U. I. and Abdullah. A. H. (2008). Heterogeneous photocatalytic degradation of organic contaminants over titanium dioxide: A review of fundamentals, progress and problems, J. Photochem. Photobiol. C: Photochemistry Reviews 9: 1-12.

Hatchard. C. G. and Parker. C. A. (1956). Proc. R. Soc. Lond., Ser. A, 235, 518.

Kuo. W. S. and Ho. P. H. (2006). Solar photocatalytic decolorization of dyes in solution with $\mathrm{TiO}_{2}$ film, Dyes Pigments 71: 157-162.

Li. J., Zheng. L., Li. L., Xian. Y. and Jin. L. (2007). Fabrication of $\mathrm{TiO}_{2} / \mathrm{Ti}$ electrode by laser-assisted anodic oxidation and its application on photoelectrocatalytic degradation of methylene blue, J. Hazard. Mater. 139: 72-78.

Mahvi, A. H., Maleki. A. and Eslami. A. (2004). Potential of rice husk and rice husk ash for phenol removal in aqueous systems, Am. J. Appl. Sci. 1(4): 321-326.

Malik. P. K. (2003). Use of activated carbons prepared from sawdust and rice-husk for adsorption of acid dyes: a case study of Acid Yellow 36, Dyes Pigments, 56: 239249.

Mahmoodi. N. M. and Arami. M. (2009). Degradation and toxicity reduction of textile wastewater using immobilized titania nanophotocatalysts, J. Photochem. Photobiol. B:Biology, 94: 20-24.
Mahmoodi. N. M. and Arami. M. (2008). Modelling and sensitivity analysis of dyes adsorption onto natural adsorbent from colored textile wastewater, J. Appl. Polym. Sci. 109: 4043-4048.

Mills. A. and Wang. J. (1999). Photobleaching of methylene blue sensitized by $\mathrm{TiO}_{2}$ : an ambiguous system, Photochem. Photobiol. A: Chem. 127: 123-134.

Rajeshwar. K., Chenthamarakshan. C. R., Goeringer. S. and Djukic. M. (2001). Titania-based heterogeneous photocatalysis: materials, mechanistic issues and implications for environmental remediation, Pure Appl. Chem. 73: 1849-1869.

Rashed. M. N. and El-Amin. A. A. (2007). Photocatalytic degradation of methyl orange in aqueous $\mathrm{TiO}_{2}$ under different solar irradiation sources, Int. J. Phys. Sci. 2: 073-081.

Sauer. T., Neto. G. C., José. H. J. and Moreira. R. F. P. M. (2002). Kinetics of photocatalytic degradation of reactive dyes in a $\mathrm{TiO}_{2}$ slurry reactor, J. Photochem. Photobiol. A: Chem. 149: 147-154.

Sultana. M. S., Islam. M. S., Saha. R. and Al-Mansur. M. A. (2009). Impact of the effluents of textile dyeing industries on the surface water quality inside D.N.D Embankment, Narayanganj, Bangladesh J. Sci. Ind. Res. 44: 65-80.

Suteu, D. and Biba. D. (2005). Equilibrium and kinetic study of reactive dye Brilliant Red HE-3B adsorption by activated charcoal, Acta Chim. Slov, 52: 73-79.

Taicheng. A., Guiying. L., Xiong. Y., Xihai. Z. and Hengtai. X, Guoguang,. L. (2001). Photoelectrochemical degradation of methylene blue with nano $\mathrm{TiO}_{2}$ under high potential bias, Mater. Phys. Mech. 4: 101-106

Received : November 09, 2009;

Accepted : March 24, 2010 